\title{
Price Discovery in Currency Markets: Evidence from Three Emerging Markets
}

\author{
Maria E. de Boyrie ${ }^{1}$, Ivelina Pavlova ${ }^{2}$ \& A. M. Parhizgari ${ }^{3}$ \\ ${ }^{1}$ New Mexico State University, United States \\ ${ }^{2}$ University of Houston - Clear Lake, United States \\ ${ }^{3}$ Florida International University, United States \\ Correspondence: Ivelina Pavlova, Asst. Professor of Finance, University of Houston - Clear Lake, 2700 Bay \\ Area Blvd., Box 70, Houston, TX 77058, USA. Tel: 1-281-283-3208. E-mail: pavlova@uhcl.edu
}

Received: October 12, 2012

Accepted: October 24, 2012 Online Published: October 26, 2012

doi:10.5539/ijef.v4n12p61

URL: http://dx.doi.org/10.5539/ijef.v4n12p61

\begin{abstract}
This study investigates the price discovery role of the spot and the futures markets for the Brazilian real, South African rand and Russian ruble. Three methodologies are employed: open-end multiple structural analyses, vector error correction model, and reduced form computation of the information shares. Within the full period of the data sample, three non-overlapping sub-periods are identified and analyzed. The findings indicate that while the futures market has a more prominent role in price discovery for the Brazilian real, the spot market has a leading position in the Russian ruble. The South African rand results are mixed. Further, the estimated short-run lead-lag results suggest that in general the dynamics of the three emerging currency markets are not the same.
\end{abstract}

Keywords: foreign exchange, futures markets, price discovery

\section{Introduction}

Price discovery studies on the currencies of the emerging markets have seldom been undertaken due to a number of still prevalent reasons. While a number of prior studies have focused on the speed of adjustment of prices in foreign exchange spot and futures markets, almost all of them have investigated the most actively traded currencies (euro, Japanese yen, Swiss franc and British pound). This preference may be attributed mainly to the smaller share of emerging currencies in the daily foreign exchange market turnover, the relatively small size of the currency futures markets, and most importantly to the lack of easily accessible data for these markets.

Unrelated to the price discovery, a few aspects of the emerging market currencies, however, are being studied. To cite a rare exception, Tornell and Yuan (2012) should be noted. Among the four major currencies that they consider, one is the Mexican peso. In another study, considering three emerging markets (Mexico, Brazil, and Hungary), Jochum and Kodres (1998) examine how the futures contracts influence their respective spot markets. Their focus, however, is more on the volatility aspects of these markets.

The dynamics of the spot and futures markets, particularly lead-lag relations and causality, have been the subject of numerous studies in the markets for commodities, stock indexes, and foreign exchange (FX), with the latter two dominating the most. The early contributions conclude that the futures market leads the spot (see, for instance, Kawaller, Koch and Koch (1987), Stoll and Whaley (1990), Chan (1992),Tang, Mak and Choi (1992), Ghosh (1993), Parhizgari, Dandapani and Battachayra (1994), Abhyankar (1995), Tse (1995), Brooks, Rew and Ritson (2001), Jiang, Fung, and Cheng (2001), and Schlusche (2009)). This finding, however, is challenged and does not seem to always hold. For example, Shyy, Vijayraghavan and Scott-Quinn (1996) and Darrat, Rahman and Zhong (2002), among others, conclude that the lead-lag relation between stock index futures and cash index prices is the other way around.

An extension of the above studies, primarily to the advanced spot and futures currency markets, have reached, for the most part, similar conclusions in the 1990s and early 2000s, i.e., that the futures market has a leading role in the price discovery. A number of hypotheses and theoretical and empirical currency forecasting models are based on this position. Recent empirical work questions this near consensus position and suggests that the spot currency market has gained the leading role in the price discovery. This is attributed, at least partially, to a number of recent developments in the spot currency market, namely, extensive trading volume, massive size, increased 
sophistication in financial technology, increased transparency in electronic trading, and increased use of trading algorithms.

Related to the causality direction, there is also a lack of consensus on the speed of adjustment of one market to the other. A number of researchers have concluded that prices adjust faster in the currency futures market than in the spot market (see, for instance Jabbour (1994), Crain and Lee (1995), Chatrath and Song (1998), and Martens and Kofman (1998)). In contrast, Cabrera, Wang and Yang (2009) and Chen and Gau (2010), among others, have reached a reverse position. Furthermore, Tse, Xiang and Fung (2006) find that the results vary based on the currency under study while Rosenberg and Traub (2009) find that the relation for the same currency is subject to change based on the trading platform and the type of futures contracts (regular vs. E-mini) used in the study.

The purpose of this paper is to investigate the lead-lag relationship between futures and spot markets, but within a fully different context. First, the emerging markets, and not the advanced ones, are the focal points since they have rarely been studied. In particular, this study considers the currency spot and futures markets for the Brazilian real, South African rand, and Russian ruble. Second, multiple structural breaks in the series, and separate consideration of market ups and downs, are taken seriously to account for possible nonlinearity in the series and to avoid reaching spurious or conflicting outcomes. Finally, prior works have shied away from studying currencies of the emerging markets because of the reasons we have already cited. The efforts in this paper are to fill this gap.

Our choice of the three emerging economy currencies is motivated in part by the recognition of Brazil, Russia and South Africa as the fastest growing emerging economies in their respective regions. (Note 1 and 2) During the period of our study (2005 to 2011) all three currencies went through periods of appreciation before 2008, and then weakening during the flight to safe havens and risk-aversion from emerging currencies during the global financial crisis. Furthermore, they experienced different degrees of foreign exchange rate interventions. In particular, throughout the sample period the Bank of Russia has been very active in the ruble market both with planned and unplanned interventions, while the South African Reserve Bank has mostly focused on accumulating reserves to manage liquidity and "lean against the wind" during periods of large capital inflows. Brazil has also intervened to protect the competitiveness of its exports.

The remaining parts of this paper are organized as follows. The next section provides a brief review of the related prior literature. Section 3 documents the sources of data. Section 4 presents the triple methodologies that we have sequentially employed, i.e., open-end multiple structural analyses, vector error correction model, and reduced form computation of the information shares. Section 5 discusses and evaluates the empirical results. The last section offers the conclusions.

\section{Selected Prior Literature}

The literature on foreign currency price discovery has already reached a near-consensus that the price discovery process depends on: a) trading platform, i.e., electronic in contrast with floor trading, b) volatility, and c) information flow as well as the content of such flow.

Using euro and Japanese yen, Tse, Xiang, and Fung (2006) determine that the electronic trading platforms are more conducive to price discovery than the floor trading. According to their results, on the electronic platforms, the futures prices lead the spot prices in the case of euro, but not for the Japanese yen, whereas the floor-traded futures markets contribute very little to the price discovery of either currency. A conflicting position is drawn when Cabrera, Wang and Yang (2009) report that information found in the spot market leads the futures market for the euro and lags for the yen. Drawing on Poskitt (2010), a reason for this controversial result lies in the differences in the methodologies that are employed in these studies. There is also a difference in measurement: returns are calculated from mid-quotes in the spot market as compared to the use of transaction prices in the futures markets.

Using floor- and electronic-traded futures contracts, Rosenberg and Traub (2009) study whether the shift to the electronic trading provides different results when examining the price discovery controversies. Considering information from 1996, the year when the shift to electronic trading in the spot market started for the British pound and the Swiss franc, and 2006 they show that prior to 1996 the amount of information discovered through currency futures was greater than those found in a post-shift era, i.e., in 2006. They also found that there were increases in spot market transparency after the shift occurred. Obviously, while a decade or so had to pass after the shift to allow the electronic market to establish itself, the authors, however, make no adjustments for the substantial changes in the technological know-how that took place during this relatively long time period.

A related strand of literature has addressed conditional variances across financial markets and their implications for information transmission among the markets. Among such contributions, Chatrath and Song (1998) establish a volatility spillover relation to determine whether price movements in the futures markets lead the price movements 
in the cash markets for the Japanese yen. They conclude that the futures price changes lead the cash price changes and that that the futures market leads the volatility in the spot market. The authors attribute their findings to the efficient reaction of the futures markets to new information.

Studying price discovery for the Japanese yen and the euro around the release of major U.S. macroeconomic announcements, Chen and Gau (2010) show that the spot market provides a greater contribution to the price discovery than the futures does, and that news releases regarding gross domestic product (GDP), employment, and durable goods have a positive impact on the price discovery of the foreign exchange futures rates. These results suggest that information flow is an important determinant in the price discovery process.

To wrap up this brief review, a concluding note is in order. Excluding Jochum and Kodres' (1998) study that considers Mexican peso, Brazilian real, and Hungarian forint spot and futures markets, all the other studies have embraced currencies of the more developed countries. In this regard, and in light of the expansions that are considered here, this study is unique in focusing on three emerging market currencies (Brazil, South Africa, and Russia) that are not relatively heavily traded. Further, this analysis seeks to determine whether these countries follow the same price discovery processes as those of the more developed, and therefore more liquid, currencies.

\section{Data and Sources}

Data are obtained from several sources. Foreign exchange spot rates on the Russian ruble, Brazilian real and South African rand are obtained from CSI (Commodity Systems, Inc.). The study focuses on these three currencies because, while several other emerging market currencies are currently trading, their price history is too short or too many values are missing, thus hindering any valid empirical work. The frequency of the data is daily and the prices are as reported at the close of the market at 5:00 p.m. in New York (Eastern Time). The spot rates are matched with currency futures data from Tradestation. The futures contracts used trade on the Chicago Mercantile Exchange (CME). (Note 3) To form the data series, the contracts are rolled over to the next most actively traded contract before their expirations based on a rule of "one day higher open interest and volume". The combined (electronic and pit) contract prices are used to form continuous series. Futures close prices are collected at 4 p.m. Central time, which is the time when Globex (the CME electronic platform) closes, and which is in full synchronization with the spot prices at 5:00 pm New York (Eastern Time).

The proportion between the pit and the electronic contracts varies, with relative increases in the latter over time. Considering each of these platforms separately is not deemed feasible because of the relative thinness of volume in each platform; splitting the combined series into pit and electronic would have caused the data to become too fragmented. The final sample spans from January 3, 2005, to March 30, 2011. The descriptive statistics for the spot and futures contracts are included in Table A1.a in the appendix.

\section{Methodology}

\subsection{Vector Error Correction Model}

A vector error correction model (VECM) along with structural break analysis are utilized using both daily spot and futures currency prices of the three emerging countries during several distinct time periods. The consideration of distinct time periods is to determine whether price discovery is dynamic, not only throughout the entire period under the study, but also across sub-periods. This feature is further expected to capture anomalies, if any, and prevent the results from being confounded due to the potential existence of nonlinearities and cyclical features. Hasbrouck (1995) information shares are also estimated for each designated sub-periods.

The following general VECM is employed:

$$
\Delta y_{t}=\alpha \beta^{\prime} y_{t-1}+\sum_{i=1}^{p-1} \Phi_{i}^{*} \Delta y_{t-i}+\varepsilon_{t}
$$

where $y$ is a vector of futures and spot prices denoted by $f$ and $s$, respectively. The notation $\Delta$ indicates the differencing operator such as $\Delta y_{t}=y_{t}-y_{t-1}$. The coeficients $\alpha$ (error correction vector)and $\beta$ are $k x r$ matrices and $\Phi_{i}^{*}$ is a $k x k$ matrix.

The covariance matrix of innovations is denoted by:

$$
\Omega=\left(\begin{array}{cc}
\sigma_{1}^{2} & \rho \sigma_{1} \sigma_{2} \\
\rho \sigma_{1} \sigma_{2} & \sigma_{2}^{2}
\end{array}\right)
$$

Anticipating that the spot and futures currency error terms may be correlated, to eliminate the contemporaneous correlation, Cholesky factorization is used through obtaining the root of $\Omega=\mathrm{M} \mathrm{M}^{\prime}$, where:

$$
M=\left(\begin{array}{cc}
m_{11} & 0 \\
m_{12} & m_{22}
\end{array}\right)=\left(\begin{array}{cc}
\sigma_{1} & 0 \\
\rho \sigma_{2} & \sigma_{2}\left(1-\rho^{2}\right)^{1 / 2}
\end{array}\right)
$$


and $\rho$ is the correlation between the error terms of spot and futures prices.

Following the notation of Baillie et al. (2002), the information shares for the futures and spot markets are estimated by $I S_{I}$ and $I S_{2}$, respectively, as:

$$
\begin{aligned}
& I S_{1}=\frac{\left(\gamma_{1} m_{11}+\gamma_{2} m_{12}\right)^{2}}{\left(\gamma_{1} m_{11}+\gamma_{2} m_{12}\right)^{2}+\left(\gamma_{2} m_{22}\right)^{2}} \\
& I S_{2}=\frac{\left(\gamma_{2} m_{22}\right)^{2}}{\left(\gamma_{1} m_{11}+\gamma_{2} m_{12}\right)^{2}+\left(\gamma_{2} m_{22}\right)^{2}}
\end{aligned}
$$

where $\gamma_{t}{ }^{\prime} \mathrm{s}$ are the error correction coefficients from the VECM in relation (1).

The upper (lower) bound of each market's information share is estimated when this market is first (second) variable in the factorization as suggested by Hasbrouck (1995). Relations (1) through (5) yield a reduced form computation of Hasbrouck's IS model. Thus, at the estimation level, the VMA representation of the VECM which is undertaken in nearly all studies using Hasbrouck's approach is bypassed. Further, it could be argued that these five relations provide a hybrid approach close to both Hasbrouck's (1995) IS and Gonzalo and Granger's (1995) PT common factor models, particularly, if $\rho$, the correlation between the error terms of spot and futures prices, are not very large (Baillie et al., 2002).

\subsection{Multiple Structural Changes in the Spot and Futures Prices}

Bai and Perron's $(1998,2003)$ multiple structural changes test for liner models are used in order to determine the number of structural breaks in the daily spot and future prices of the Brazilian real, African rand, and Russian ruble.

The pure structural change model to determine $\mathrm{m}$ breaks and $\mathrm{m}+1$ subsamples is represented by:

$$
y_{t}=z_{t}^{\prime} \delta_{j}+u_{t}
$$

for $\mathrm{j}=1, \ldots, \mathrm{m}+1$, and $t=T_{j-1}+1, \ldots, T_{j}$, where $T_{j}$ represents the break points which are treated as unknowns, $y_{t}$ is the dependent variable at time t, $z_{t}$ is a qx1 vector of covariances with $\delta_{j}$ as its respective vector of coefficients, and $u_{t}$ is the disturbance at time t. The estimation method is based on the least squares principle. For each m-partition, the associated least-squares estimates of $\delta_{j}$ are obtained by minimizing the sum of squared residuals:

$$
S_{T}\left(T_{1}, \ldots, T_{n}\right)=\sum_{i=1}^{m+1} \sum_{t=T_{i-1}+1}^{T_{i}}\left[y_{t}-\delta_{i}\right]^{2}
$$

In addition, Bai and Perron $(1998,2003)$ show that the break-point estimators are global minimizers of the objective function. (Note 4) For the estimation procedure, they propose an algorithm based on a dynamic programming principle that allows the computation of estimates of the break points as global minimizers of the sum of squared residuals. (Note 5) Furthermore, in order to identify the number of breaks, the double maximum statistics needs to be examined to determine if any structural breaks are present. If these statistics are significant, then the sequence of $\operatorname{Sup}_{T}(\ell+1 \mid \ell)$ statistics must be examined, where $\ell$ represents the breaks and is used to test whether the additional breaks lead to a significant reduction in the sum of the squared residuals. (Note 6)

\section{Empirical Results}

The first step in the empirical analysis is to test all the series for stationarity and the existence of structural breaks in them. As to the stationarity, using Augmented Dickey-Fuller (1979) and Phillips-Perron (1988) tests, it is documented that the futures and the spot prices in levels contain unit root, while their returns are stationary. On the cointegration, Johansen's (1988) rank test results provide evidence that the futures and the spot series for all the three currencies are cointegrated. The results of the unit root tests and the cointegration rank tests, along with preliminary statistics on the data, are reported in Appendix 1 Tables A1.a through A1.c.

As to the structural breaks, the starting model which is tested is set with a single constant as regressor $\left(z_{t}=1\right)$. Further, it is allowed to encounter a maximum of five breaks, while using a trimming of $\varepsilon=0.05$. (Note 7) Non-parametric adjustments are allowed in order to account for possible serial correlation, while, serial correlation in the errors and different variances of the results across segments are also allowed.

Implementing the above refinements within the Bai and Perron's $(1998,2003)$ multiple structural break tests that are discussed in the methodology section, estimates of the break point dates are obtained. The results are presented in Tables 1 and 2. The break dates, which are presented in Table 2, are determined based on the results in Table 2. For each currency, there exist at least five breaks in the structure of each of the spot and the futures prices - with the exception of the spot prices for the Russian Ruble since the SupF (5|4) statistics is insignificant. Therefore, only four breaks are considered in this instance. Considering these results and given that the spot and 
the future series are each independently analyzed for the existence of the breaks, it is interesting to note that most of the break points that are identified for the spot prices are similar to those of the futures prices.

The numbers in parentheses in Table 2 represent confidence intervals at the 90 percent significance level. In most instances these appear to be large, however given that the data may not be available for every single day, the true number of observations tends to be smaller. The bold numbers and the numbers in italics represent the smallest confidence interval, followed by the second smallest interval, respectively.

Table 1. Break Dates Estimated Using Bai \& Perron's Structural Change Model

\begin{tabular}{lccccc}
\hline & $\widehat{T}_{1}$ & $\widehat{T}_{2}$ & $\widehat{T}_{3}$ & $\widehat{T}_{4}$ & $\widehat{T}_{5}$ \\
\hline \multirow{3}{*}{ Real - spot } & $9 / 16 / 2005$ & $3 / 30 / 2007$ & $10 / 4 / 2007$ & $9 / 26 / 2008$ & $7 / 14 / 2009$ \\
& $(8 / 30 / 05-1 / 06 / 06)$ & $(2 / 05 / 07-4 / 26 / 07)$ & $(1 / 24 / 07-10 / 18 / 07)$ & $(9 / 2 / 08-12 / 05 / 08)$ & $(6 / 25 / 09-8 / 26 / 09)$ \\
& $9 / 2 / 2005$ & $3 / 29 / 2007$ & $10 / 4 / 2007$ & $10 / 1 / 2008$ & $5 / 28 / 2009$ \\
Real - futures & $(8 / 12 / 05-2 / 07 / 06)$ & $(1 / 12 / 07-5 / 03 / 07)$ & $(9 / 20 / 06-10 / 17 / 07)$ & $(9 / 30 / 08-1 / 08 / 09)$ & $(4 / 09 / 09-6 / 02 / 09)$ \\
& $6 / 5 / 2006$ & $2 / 1 / 2008$ & $10 / 3 / 2008$ & $4 / 2 / 2009$ & $9 / 8 / 2010$ \\
Rand - spot & $(4 / 17 / 06-8 / 9 / 06)$ & $(1 / 11 / 08-5 / 15 / 08)$ & $(10 / 01 / 08-10 / 10 / 08)$ & $(3 / 20 / 09-4 / 2 / 09)$ & $(8 / 18 / 10-9 / 24 / 10)$ \\
& $6 / 5 / 2006$ & $1 / 30 / 2008$ & $10 / 3 / 2008$ & $4 / 2 / 2009$ & $8 / 31 / 2010$ \\
Rand -futures & $(4 / 25 / 06-8 / 15 / 06)$ & $(12 / 13 / 07-4 / 21 / 08)$ & $(10 / 01 / 08-10 / 15 / 08)$ & $(3 / 20 / 09-5 / 22 / 09)$ & $(8 / 10 / 10-9 / 20 / 10)$ \\
& $9 / 19 / 2007$ & $9 / 4 / 2008$ & $1 / 6 / 2009$ & $5 / 18 / 2009$ & $(5 / 18 / 09-7 / 20 / 09)$ \\
Ruble - spot & $(9 / 19 / 07-9 / 29 / 10)$ & $(9 / 10 / 07-9 / 4 / 08)$ & $(1 / 6 / 09-6 / 1 / 09)$ & $5 / 16 / 2009$ \\
& $5 / 1 / 2006$ & $9 / 11 / 2007$ & $10 / 16 / 2008$ & $5 / 1 / 2009$ & $(8 / 13 / 09-10 / 01 / 09)$ \\
\hline
\end{tabular}

For illustrative purposes, Figures 1.a through 1.c portray the spot and the futures prices for the Brazilian real, the South African rand, and the Russian ruble and their changing means. In all figures, it appears that the futures contracts lead the spot. This graphical and non-statistical observation remains to be tested rigorously to see if it holds or not.

Prior to analyzing the price discovery process, each series is divided into three sub-samples based on the results presented in Table 2 and a few other considerations. The full sample includes the entire sample period from January 3, 2005 to March 30, 2011. The three sub-samples are defined over the following sub-periods presented in table 3 . 
Table 2. Empirical Results of Bai \& Perron's Structural Change Models for Brazilian Real, African Rand, and Russian Ruble Spot and Futures Prices

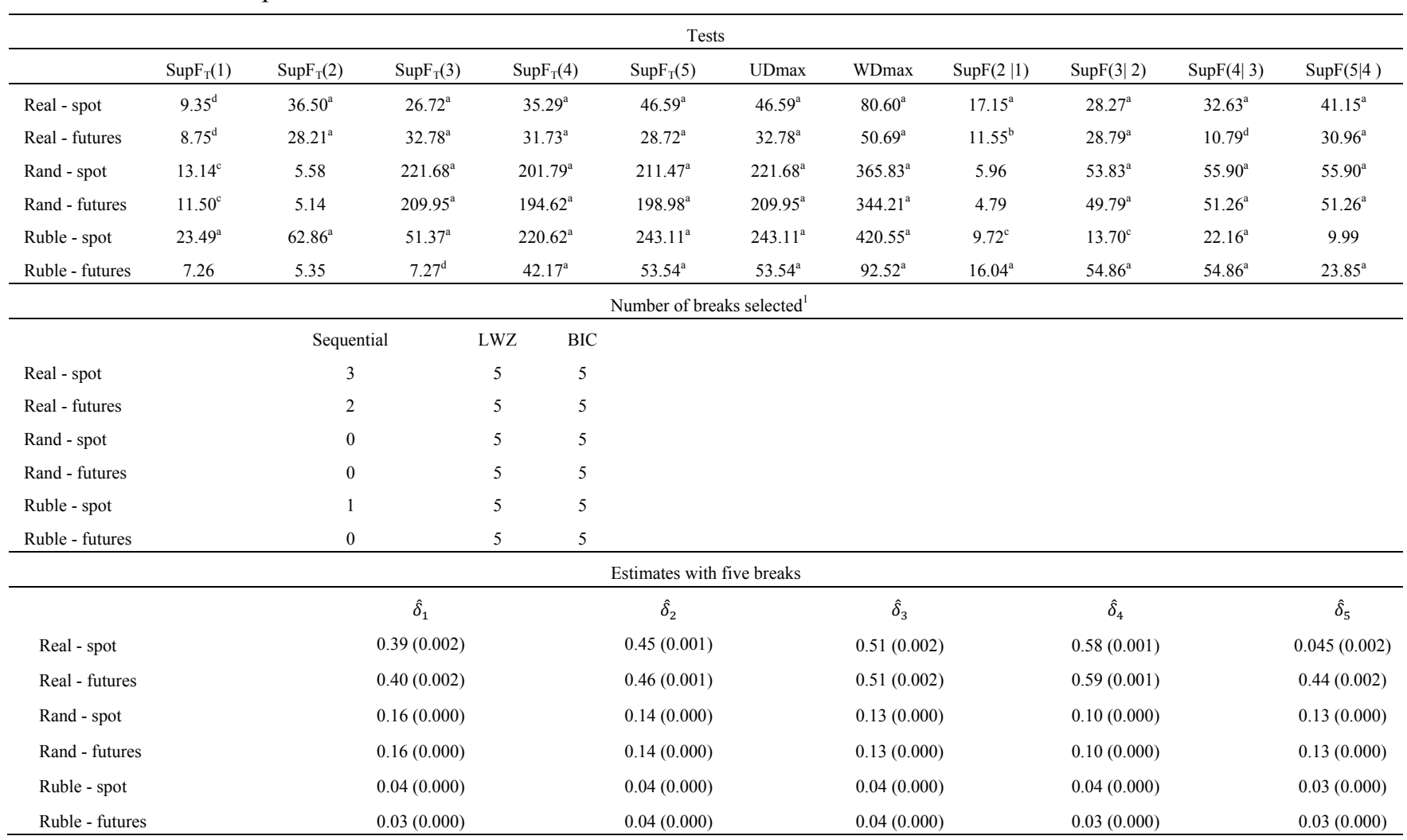

${ }^{1} \mathrm{LWZ}$ stands for the modified Schwarz criterion of Liu et al. (1997) and BIC for Bayesian Information Criterion.

${ }^{\mathrm{a}, \mathrm{b}, \mathrm{c}, \mathrm{d}}$ Significant at the $1,2.5,5$, and 10 percent levels, respectively.

Figures in parentheses represent the standard errors for $90 \%$ confidence intervals for $\hat{\delta}_{i}$.

$\hat{\delta}_{i} \mathrm{I}$ is the estimate of the dynamic programming algorithm.

UDmax represents the results of the equal weighted double maximum test (test of the null hypothesis of no structural break against an unknown number of breaks given some upper bound); while WDmax represents a double maximum test in which weights are applied to the individual tests.

Table 3. Subsamples

\begin{tabular}{llll}
\hline & Sub-sample 1 & Sub-sample 2 & Sub-sample 3 \\
\hline Brazilian real & $01 / 03 / 05-10 / 04 / 07$ & $10 / 05 / 07-10 / 01 / 08$ & $10 / 02 / 08-03 / 30 / 11$ \\
South African rand & $01 / 03 / 05-10 / 03 / 08$ & $10 / 04 / 08-04 / 02 / 09$ & $04 / 03 / 09-03 / 30 / 11$ \\
Russian ruble & $01 / 03 / 05-10 / 16 / 08$ & $10 / 17 / 08-09 / 16 / 09$ & $09 / 17 / 09-03 / 30 / 11$ \\
\hline
\end{tabular}




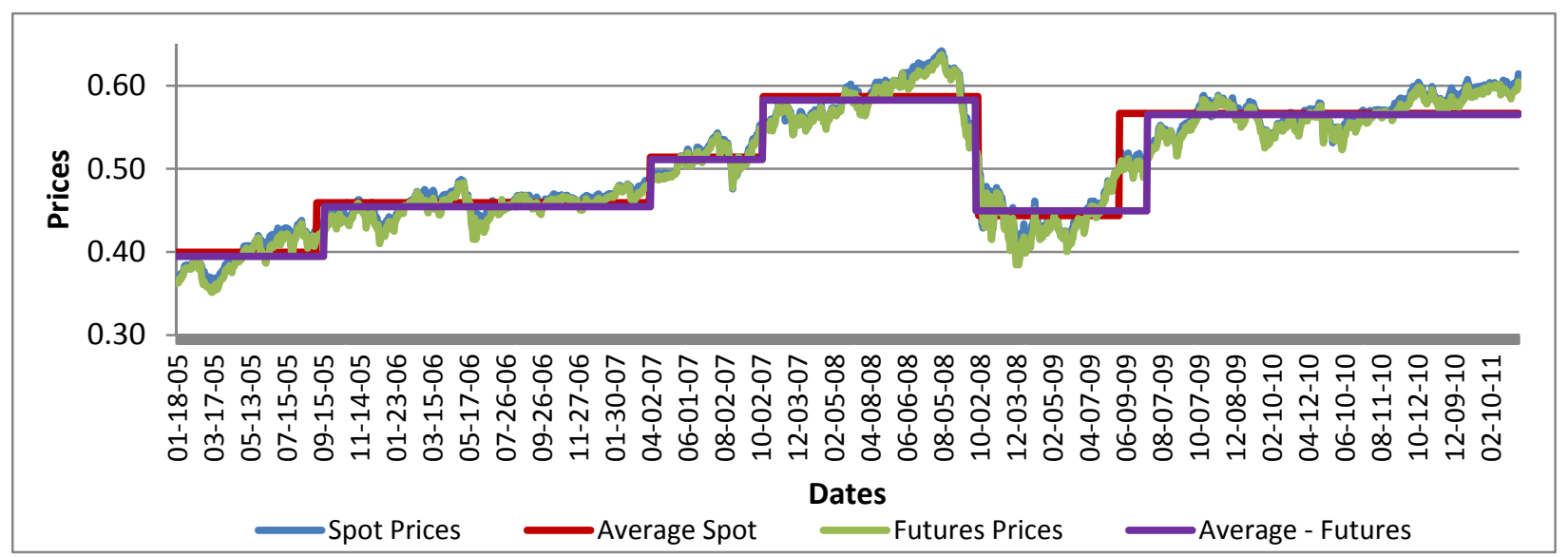

Figure 1a. Brazilian Real - Spot and Futures Prices with their respective change in means

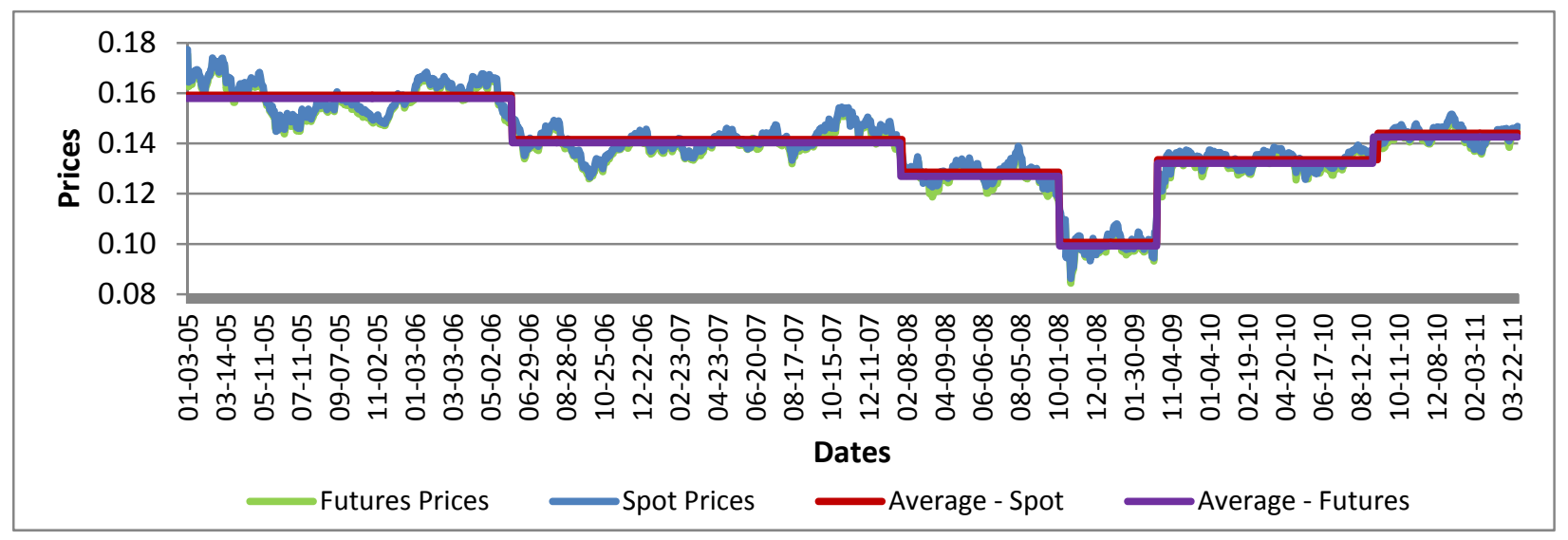

Figure 1b. South African Rand - Spot and Futures Prices with their respective change in means

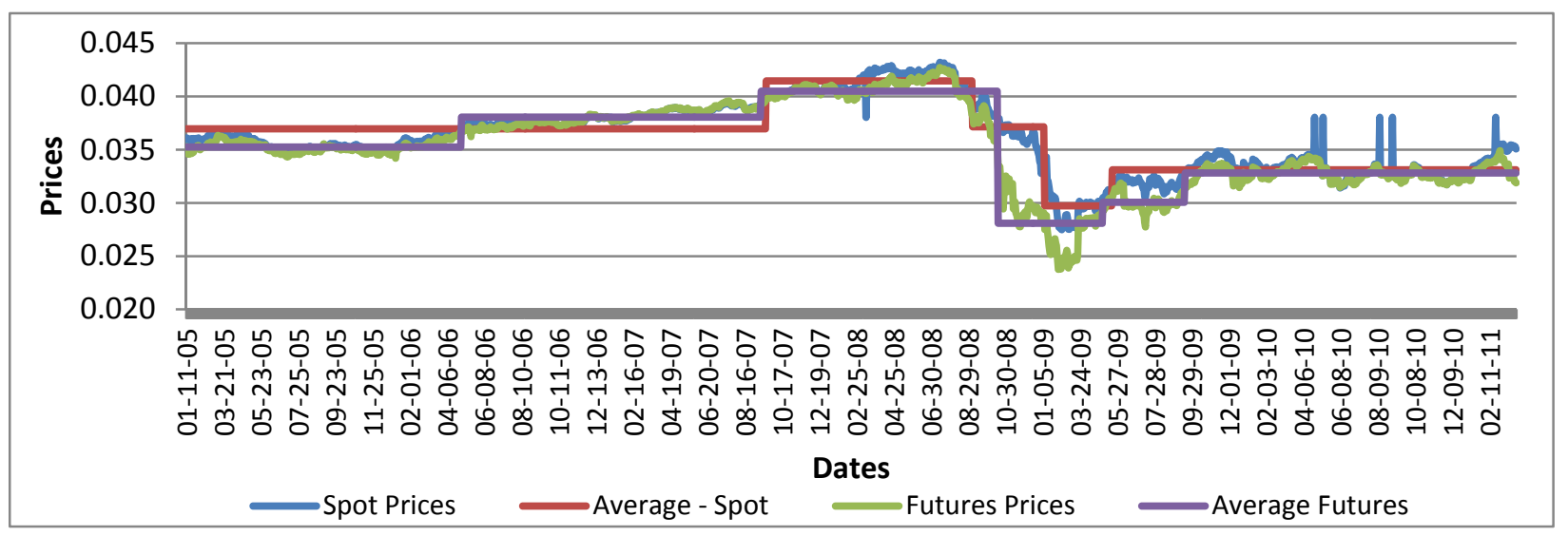

Figure 1c. Russian Ruble - Spot and Futures Prices with their respective change in means 
Considering Figures 1a through 1c, the first subsample for the Brazilian real represents a period of consistent growth in the spot and the futures prices wherein both reach their highest levels. Sub-sample 2 is a period of sheer declines and sub-sample 3 is a period of gradual recovery.

Unlike the trend shown in the Brazilian real, the South African rand has a period of decline in both its spot and futures prices until the end of the first sub-sample when they reach their lowest levels; then they begin to recover in the second sub-sample. The third sub-sample is one of stability and some growth.

The spot and the futures prices for the Russian ruble do not follow each other as closely as seen in the cases of the real and the rand, yet the first sub-sample for the ruble can be described as one of stability and small growth. During the second sub-sample they start to decline and both prices reach their lowest levels. Recovery and stability are seen in the third sub-sample.

Given the above dynamic patterns in the series, it is possible that the results based on the full sample and a linear model, which is the case in nearly all prior studies, may be confounded on statistical as well as on "wash-out" grounds. This may also provide an explanation why some of the prior findings are inconsistent.

The estimation of the vector error correction model (VECM) as defined in relation (1) is then undertaken without considering any exogenous variables. This approach is quite in-line with nearly all prior studies. In all cases, the optimal lag length for each currency is sought based on BIC.The results of the VECM estimation are included in Table 4. The bold numbers in this Table indicate statistical significance at the 5 percent or below. The full sample is divided into the three sub-smaples as discussed above on the basis of the breakpoints in each currrency, i.e.: Brazilian real (Ocober 4, 2007 to Ocotber 1, 2008), South African rand (October 3, 2008 to April 2, 2009) and Russian Ruble (Ocotber 16, 2008 to Sepetmber 16, 2009), etc. Each Table contains four samples: the full sample and the three sub-samples. Finally, the information shares are computed based on the error correction coefficient estimates in Table 4 and the factored innovation matrix of the estimated VECM. These results are reported in Table 5.

Considering Table 4, a few observations on the short-run dynamics between the futures and spot prices are in order. Such observations are often made based on the magnitude of the coefficients of the lagged difference terms $\left(\Delta s_{t-i}\right.$ and $\left.\Delta f_{t-i}\right)$. It is of interest to observe whether changes in yesterday's spot returns have any influence on today's futures returns and vice versa, thereby establishing a leading role, if any, in price discovery for one of these markets and examining if that role is changing over time. The consensus in this regard has been shifting. For instance, even though the foreign exchange spot market in general has significantly higher volume than the futures market, some studies have shown that the futures markets lead the spot due to lower transaction costs, high leverage, and transparency (Stoll and Whaley, 1990; Tse, Xiang and Fung, 2006).

The results for the Brazilian real show that the spot market has the leading role. The first lag of the spot return has significant influence on the futures return over the full sample and two of the subsamples. In contrast, the first lag of the futures return is not significant in explaining the spot return in any of the subsamples or the full sample, though it is highly significant at two lags. The same pattern is nearly present for South African rand $\left(\Delta s_{t-i}\right.$ is significant in the full sample and subsamples 1 and 2). However, a notable pattern emerges in the rand's results towards the end of our data sample, i.e., the futures markets appear to assume a more important role; the lagged futures return influences the spot in subsamples 2 and 3. The VECM results for the ruble show mixed results, where both lagged futures and spot returns have a role in price discovery.

Overall, the results presented in Table 4 support the notion that both futures and spot markets play a role in price discovery in the three emerging markets studied. The results are mixed, particularly across the sub-samples. Stated differently, there is ample indication that the ups and the downs in the market have some influences on the results. Therefore, bundling these markets together, as has been the practice in prior studies, may confound the outcome.

Table 5 reports estimates of the information shares for the three currencies for the full sample as well as the subsamples defined by the structural breaks. The upper and the lower boundaries are presented in brackets below the mid-point information shares. 
Table 4. VECM Estimates

\begin{tabular}{|c|c|c|c|c|c|c|c|c|c|}
\hline \multirow[b]{2}{*}{ Equation } & \multirow[b]{2}{*}{ Variable } & \multicolumn{2}{|c|}{ Full sample } & \multicolumn{2}{|c|}{ Subsample 1} & \multicolumn{2}{|c|}{ Subsample 2} & \multicolumn{2}{|c|}{ Subsample 3} \\
\hline & & Estimate & t Value & Estimate & t Value & Estimate & t Value & Estimate & t Value \\
\hline \multicolumn{10}{|c|}{ Brazilian Real } \\
\hline \multirow[t]{7}{*}{$\Delta f_{t}$} & Intercept & 0.001 & 2.11 & 0.004 & 3.34 & 0.002 & 0.78 & 0.000 & 0.82 \\
\hline & $f_{t-1}$ & -0.158 & -4.01 & -0.145 & -2.96 & 0.110 & 0.93 & -0.262 & -3.67 \\
\hline & $s_{t-1}$ & 0.161 & 4.01 & 0.151 & 2.96 & -0.107 & -0.93 & 0.266 & 3.67 \\
\hline & $\Delta f_{t-1}$ & -0.316 & -6.34 & -0.230 & -3.49 & -0.254 & -1.61 & -0.380 & -4.70 \\
\hline & $\Delta s_{t-1}$ & 0.304 & 6.04 & 0.212 & 2.78 & 0.206 & 1.4 & 0.351 & 4.46 \\
\hline & $\Delta f_{t-2}$ & -0.044 & -0.98 & -0.245 & -4.00 & 0.104 & 0.73 & 0.098 & 1.41 \\
\hline & $\Delta s_{t-2}$ & 0.010 & 0.21 & 0.206 & 2.90 & -0.231 & -1.72 & -0.106 & -1.49 \\
\hline \multirow[t]{7}{*}{$\Delta s_{t}$} & Intercept & 0.000 & 0.69 & -0.001 & -0.78 & 0.006 & 2.32 & 0.001 & 0.98 \\
\hline & $f_{t-1}$ & 0.086 & 2.19 & 0.064 & 1.50 & 0.294 & 2.48 & 0.082 & 1.07 \\
\hline & $s_{t-1}$ & -0.087 & -2.19 & -0.066 & -1.50 & -0.286 & -2.48 & -0.084 & -1.07 \\
\hline & $\Delta f_{t-1}$ & -0.011 & -0.21 & 0.072 & 1.27 & 0.225 & 1.42 & -0.140 & -1.60 \\
\hline & $\Delta s_{t-1}$ & -0.040 & -0.8 & -0.091 & -1.38 & -0.295 & -1.99 & 0.065 & 0.76 \\
\hline & $\Delta f_{t-2}$ & 0.134 & 3.01 & -0.099 & -1.87 & 0.402 & 2.83 & 0.260 & 3.48 \\
\hline & $\Delta s_{t-2}$ & -0.176 & -3.76 & 0.052 & 0.85 & -0.516 & -3.83 & -0.267 & -3.46 \\
\hline \multicolumn{10}{|c|}{ South African Rand } \\
\hline \multirow[t]{7}{*}{$\Delta f_{t}$} & Intercept & 0.004 & 2.63 & 0.006 & 2.65 & -0.006 & -0.29 & -0.006 & -1.67 \\
\hline & $f_{t-1}$ & -0.168 & -2.77 & -0.191 & -2.85 & 0.071 & 0.30 & -0.204 & -1.82 \\
\hline & $s_{t-1}$ & 0.171 & 2.77 & 0.195 & 2.85 & -0.074 & -0.30 & 0.202 & 1.82 \\
\hline & $\Delta f_{t-1}$ & -0.294 & -4.49 & -0.134 & -1.76 & -0.894 & -3.76 & -0.049 & -0.34 \\
\hline & $\Delta s_{t-1}$ & 0.398 & 6.26 & 0.195 & 2.53 & 0.896 & 4.05 & 0.093 & 0.62 \\
\hline & $\Delta f_{t-2}$ & 0.019 & 0.35 & -0.030 & -0.46 & 0.027 & 0.16 & -0.081 & -0.61 \\
\hline & $\Delta s_{t-2}$ & 0.018 & 0.33 & 0.022 & 0.33 & 0.196 & 1.09 & 0.059 & 0.45 \\
\hline \multirow[t]{7}{*}{$\Delta s_{t}$} & Intercept & -0.005 & -3.31 & -0.005 & -2.24 & -0.062 & -2.35 & 0.001 & 0.26 \\
\hline & $f_{t-1}$ & 0.218 & 3.34 & 0.142 & 2.09 & 0.701 & 2.37 & 0.015 & 0.14 \\
\hline & $s_{t-1}$ & -0.222 & -3.34 & -0.145 & -2.09 & -0.732 & -2.37 & -0.015 & -0.14 \\
\hline & $\Delta f_{t-1}$ & -0.047 & -0.66 & 0.144 & 1.86 & -0.873 & -2.94 & 0.388 & 2.71 \\
\hline & $\Delta s_{t-1}$ & 0.093 & 1.36 & -0.103 & -1.32 & 0.764 & 2.77 & -0.372 & -2.55 \\
\hline & $\Delta f_{t-2}$ & 0.160 & 2.76 & 0.091 & 1.34 & 0.084 & 0.39 & 0.021 & 0.16 \\
\hline & $\Delta s_{t-2}$ & -0.147 & -2.46 & -0.113 & -1.64 & 0.108 & 0.48 & -0.057 & -0.44 \\
\hline \multicolumn{10}{|l|}{ Ruble } \\
\hline \multirow[t]{9}{*}{$\Delta f_{t}$} & Intercept & -0.010 & -2.63 & -0.004 & -1.11 & -0.102 & -1.94 & -0.037 & -1.42 \\
\hline & $f_{t-1}$ & 0.014 & 2.62 & 0.011 & 1.12 & -0.042 & -1.94 & -0.039 & -1.42 \\
\hline & $s_{t-1}$ & -0.017 & -2.62 & -0.012 & -1.12 & 0.013 & 1.94 & 0.028 & 1.42 \\
\hline & $\Delta f_{t-1}$ & 0.056 & 2.01 & -0.139 & -3.61 & -0.008 & -0.09 & 0.040 & 0.71 \\
\hline & $\Delta s_{t-1}$ & 0.070 & 3.37 & 0.073 & 2.32 & 0.384 & 2.67 & -0.001 & -0.03 \\
\hline & $\Delta f_{t-2}$ & -0.077 & -2.76 & 0.017 & 0.42 & -0.115 & -1.26 & -0.088 & -1.63 \\
\hline & $\Delta s_{t-2}$ & 0.036 & 1.56 & 0.041 & 1.19 & 0.132 & 0.92 & -0.011 & -0.46 \\
\hline & $\Delta f_{t-3}$ & -0.073 & -2.72 & 0.023 & 0.59 & -0.071 & -0.79 & 0.039 & 0.74 \\
\hline & $\Delta s_{t-3}$ & 0.006 & 0.28 & 0.037 & 1.23 & -0.017 & -0.12 & -0.015 & -0.78 \\
\hline \multirow[t]{9}{*}{$\Delta s_{t}$} & Intercept & -0.025 & -5.23 & -0.006 & -1.58 & 0.011 & 0.33 & 0.224 & 3.18 \\
\hline & $f_{t-1}$ & 0.036 & 5.24 & 0.019 & 1.61 & 0.005 & 0.35 & 0.233 & 3.18 \\
\hline & $s_{t-1}$ & -0.044 & -5.24 & -0.021 & -1.61 & -0.002 & -0.35 & -0.168 & -3.18 \\
\hline & $\Delta f_{t-1}$ & 0.321 & 8.80 & 0.470 & 10.19 & 0.032 & 0.53 & 0.200 & 1.34 \\
\hline & $\Delta s_{t-1}$ & -0.567 & -20.85 & -0.594 & -15.74 & 0.115 & 1.23 & -0.604 & -9.36 \\
\hline & $\Delta f_{t-2}$ & 0.087 & 2.37 & 0.352 & 7.13 & -0.144 & -2.43 & 0.062 & 0.42 \\
\hline & $\Delta s_{t-2}$ & -0.315 & -10.35 & -0.384 & -9.23 & 0.130 & 1.38 & -0.386 & -6.00 \\
\hline & $\Delta f_{t-3}$ & 0.102 & 2.86 & 0.229 & 4.95 & 0.054 & 0.91 & 0.195 & 1.37 \\
\hline & $\Delta s_{t-3}$ & -0.149 & -5.53 & -0.206 & -5.67 & -0.039 & -0.42 & -0.192 & -3.68 \\
\hline
\end{tabular}

This table reports VECM coefficient estimates for the following model:

$\Delta y_{t}=\alpha \beta^{\prime} y_{t-1}+\sum_{i=1}^{p-1} \Phi_{i}^{*} \Delta y_{t-i}+\varepsilon_{t}$

where $y$ is a vector of $\log$ futures and spot prices denoted by $f$ and $s$, respectively and $\Delta$ is the difference operator.The optimal lag length for each currency is based on BIC. The numbers in bold indicate statistical significance at 5 percent or below. The full sample is divided into three subsmaples based on the following breakpoints for each currrency: Brazilian real - Ocober 4, 2007 to Ocotber 1, 2008; Southafrican rand - October 3, 2008 to April 2, 2009; and Russian Ruble - Ocotber 16, 2008 to Sepetmber 16, 2009. 
Table 5. Information Shares

\begin{tabular}{lcccc}
\hline & \multicolumn{2}{c}{ Full sample } & \multicolumn{2}{c}{ Subsample 1 } \\
\hline Currency & $I S_{F}$ & $I S_{S}$ & $I S_{F}$ & $I S_{S}$ \\
\hline Brazilian Real & 0.77 & 0.22 & 0.8 & 0.2 \\
South African Rand & {$[0.773,0.777]$} & {$[0.223,0.227]$} & {$[0.706,0.898]$} & {$[0.102,0.294]$} \\
& 0.29 & 0.71 & 0.7 & 0.3 \\
Russian Ruble & {$[0.128,0.445]$} & {$[0.555,0.872]$} & {$[0.469,0.936]$} & {$[0.064,0.531]$} \\
& 0.2 & 0.8 & 0.33 & 0.67 \\
& {$[0.055,0.339]$} & {$[0.661,0.945]$} & {$[0.105,0.563]$} & {$[0.437,0.895]$} \\
\hline \multicolumn{2}{c}{ Subsample 2} & \multicolumn{2}{c}{ Subsample 3} \\
Brazilian Real & $I S_{F}$ & $I S_{S}$ & $I S_{F}$ & $I S_{S}$ \\
South African Rand & 0.45 & 0.55 & 0.74 & 0.26 \\
Russian Ruble & {$[0.015,0.892]$} & {$[0.108,0.985]$} & {$[0.538,0.938]$} & {$[0.062,0.462]$} \\
& 0.4 & 0.6 & 0.59 & 0.41 \\
& {$[0.001,0.808]$} & {$[0.192,0.999]$} & {$[0.173,0.999]$} & {$[0.000,0.827]$} \\
& 0.5 & 0.5 & 0.02 & 0.98 \\
& {$[0.141,0.868]$} & {$[0.132,0.859]$} & {$[0.000,0.045]$} & {$[0.955,1.000]$} \\
\hline
\end{tabular}

This table reports the mid-points and the upper and lower bounds of the information shares of futures $\left(I S_{F}\right)$ and spot $\left(I S_{S}\right)$ markets for the three currencies. The upper $\left(H_{U B}\right)$ and the lower $\left(H_{L B}\right)$ bounds are reported in brackets below the mid-point information shares. The full sample is divided into three subsmaples based on the following breakpoints for each currrency: Brazilian real - Ocober 4, 2007 to Ocotber 1, 2008; Southafrican rand - October 3, 2008 to April 2, 2009; and Russian Ruble - Ocotber 16, 2008 to Sepetmber 16, 2009.

The information shares of the futures and spot markets differ by currency as well as across the sub-periods. For Brazilian real, the futures lead the spot in all samples except subsample 2 which includes the $2008-2009$ period. The results for the South African rand are mixed. In the case of the Russian ruble, the spot lead the futures in all periods except for the period of crisis in which there was no lead/lag effect. If at all, during the second subsample the futures market leads spot by the smallest of margins ( 0.504 vs. 0.496$)$.

The second sub-period that coincides with the global financial crisis is of special interest and it shows different IS patterns for the three currencies. During this sup-period, the spot leads the futures for two of the currencies Brazilian Real and South African Rand, while for Russian ruble there is almost no predominant market position in price discovery.

It should also be noted that while the information shares could more accurately be estimated with high frequency data, using lower frequency data can pose challenges. For instance, it leads to wider bands for the estimated information shares. This is a well-known factor in the price discovery literature. Using several studies with different data frequencies, Baillie et al. (2002) show that at one second intervals the upper and the lower bands are almost the same, while at frequencies of one minute and higher the boundaries can diverge significantly. The results presented in the current study are consistent with and reflect these points as well.

In sum, the short-run dynamics from the VECM and the computed information shares provide evidence in support of the important roles that the futures and the spot markets may play in price discovery. The influence of each market is not constant over time or for each currency. The futures market appears to be more prominent in Brazilian real price discovery process, while the spot has overall a leading role in the Russian ruble market.

Finally, the response of the estimated VECM to some perturbations is examined. This could be regarded, at minimum, a test of the dynamics and the sensitivity of the model. This is performed through impulse response functions wherein the system is traced under a one standard deviation shock in either the spot or in the futures market for each currency. The results are plotted in Figures 2.a through 2.d. Each graph indicates the impact path of a shock in a given variable over time. The vertical axis represents the deviation (return increment) from the benchmark case, while the horizontal axis represents the days elapsed post the initial shock. In general, the results conform to those in prior studies. The shock impact tends to amplify first, and then it starts to dissipate. As expected, the dynamics of the three currencies are not the same: the shocks result in the highest impact during the second or the third days and dissipate to near zero in five to six days. Some persistence, though not necessarily significant, seem to be present. 


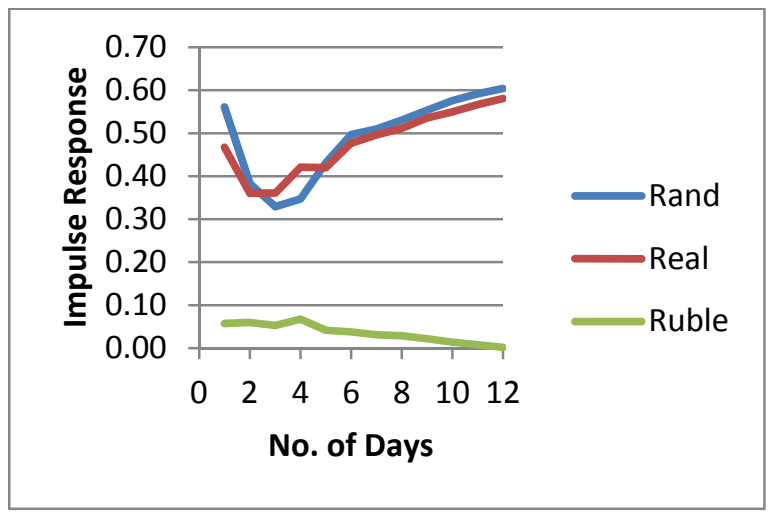

Figure 2a. Impulse Response Function - Response of Futures Return to Change in Spot Return

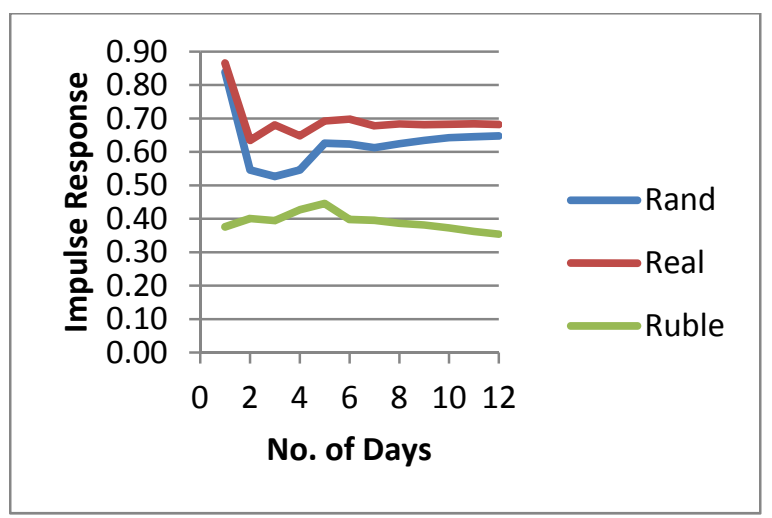

Figure 2c. Impulse Response Function - Response of Spot Return to Change in Spot Return

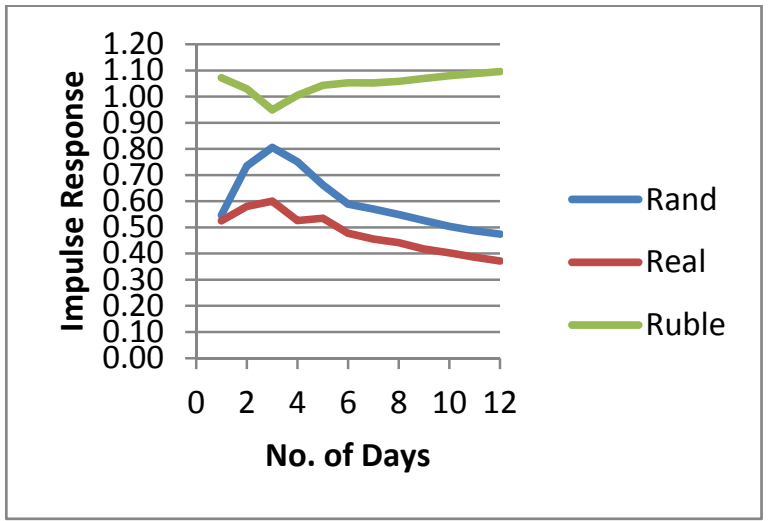

Figure 2b. Impulse Response Function - Response of Futures Return to Change in Futures Return

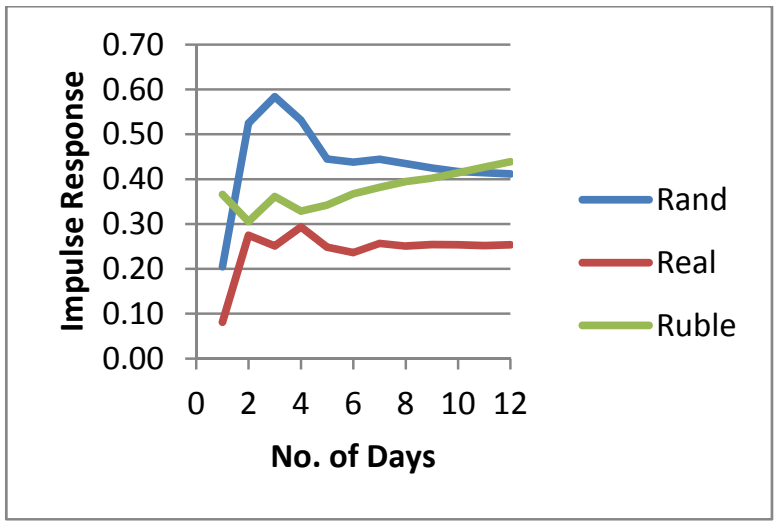

Figure 2d. Impulse Response Function - Response of Spot Return to Change in Futures Return

\section{Conclusions}

This study has investigated the price discovery for three emerging market spot and futures currencies (Brazilian real, South African rand and Russian ruble). Prior to the analysis, multiple structural breaks in the series are carefully examined to account for possible nonlinearity in the series and to avoid reaching spurious or conflicting outcomes. The presence of multiple structural breaks in the series adds additional value to our results. The outcomes of the structural break analyses yield four distinctive samples that we have individually analyzed. These varied alternatives add invaluable information to the literature on price discovery. In addition to the full sample, each of the three sub-samples is separately analyzed. It is shown that the dynamics of these sub-samples are not the same and rolling them into one long sample may wash out the diverse outcomes or confound the results.

The results based on the VECM estimates and the derived information shares lead us to conclude that both futures and spot markets play a role in price discovery for the three emerging currencies studied. Whereas the futures markets appears leading in the case of the Brazilian real, the spot has more influence for the Russian ruble. The results for the rand are mixed. The sub-samples estimates further reveal the impact of market turbulence on the lead-lag relations, as the information shares of futures and spot markets change for all three currencies during the second sub-period. Given the differences in the underlying factors and in particular across the sub-samples, it is worthwhile to reiterate that seeking uniformity across all markets and over all time periods is unwarranted.

A possible extension of this study is to investigate further whether the changing roles of the futures and spot markets in the price discovery process is associated with such market characteristics such as volatility and liquidity in the subsamples that we have designated. The information shares could be estimated using a VECM which includes variables such as spot or futures market volume, return volatility, stock market interaction variables and others. 


\section{References}

Abhyankar, A. H. (1995). Return and volatility dynamics in the FT-SE 100 stock index and stock index futures markets. Journal of Futures Markets, 15, 457-488. http://dx.doi.org/10.1002/fut.3990150405

Bai, J., \& Perron, P. (1998). Estimating and testing linear models with multiple structural changes. Econometrica, 66, 47-78. http://dx.doi.org/10.2307/2998540

Bai, J., \& Perron, P. (2000). Multiple structural change models: A simulation analysis. Econometric Essays, D. Corbea, S. Durlauf and B. E. Hansen (Ed.), Cambridge University Press.

Bai, J., \& Perron, P. (2003). Computation and analysis of multiple structural change models. Journal of Applied Econometrics, 18, 1-22. http://dx.doi.org/10.1002/jae.659

Baillie, R. T., Booth, G. G., Tse, Y. K., \& Zabotina, T. (2002). Price discovery and common factor models. Journal of Financial Markets, 5, 309-321. http://dx.doi.org/10.1016/S1386-4181(02)00027-7

Brooks, C., Rew, A. G., \& Ritson, S. (2001). A trading strategy based on the lead-lag relationship between the spot index and futures contract for the FTSE 100. International Journal of Forecasting, 17, 31-44. http://dx.doi.org/10.1016/S0169-2070(00)00062-5

Cabrera, J., Wang, T., \& Yang, J. (2009). Do futures lead price discovery in electronic foreign exchange markets? The Journal of Futures Markets, 29, 137-156. http://dx.doi.org/10.1002/fut.20352

Chan, K. (1992). A Further Analysis of the lead-lag relationship between the cash market and stock index futures market. Review of Financial Studies, 5, 123-152. http://dx.doi.org/10.1093/rfs/5.1.123

Chatrath, A., \& Song, F. (1998). Information and volatility in futures and spot markets: The case of the Japanese $\begin{array}{lllll}\text { yen. The Journal of Futures } & \text { 201-223. }\end{array}$ http://dx.doi.org/10.1002/(SICI)1096-9934(199804)18:2<201::AID-FUT5>3.0.CO;2-V

Chen, Y. L., \& Gau, Y. F. (2010). News announcements and price discovery in foreign exchange spot and futures markets. Journal of Banking \& Finance, 34, 1628-1636. http://dx.doi.org/10.1016/j.jbankfin.2010.03.009

Crain, S. J., \& Lee, J. H. (1995). Intraday volatility in interest rate and foreign exchange spot and futures markets. The Journal of Futures Markets, 15, 395-421. http://dx.doi.org/10.1002/fut.3990150403

Darrat, A. F., Rahman, S., \& Zhong, M. (2002). On the role of futures trading in spot market fluctuations: Perpetrator of volatility or victim of regret. Journal of Financial Research, XXV, 431-444. http://dx.doi.org/10.1111/1475-6803.00028

Dickey, D. A., \& Fuller, W. A. (1979). Distribution of the estimators for autoregressive time series with a unit root. Journal of the American Statistical Association, 74, 427-437.

Ghosh, A. (1993). Cointegration and error correction models: Intertemporal causality between index and futures prices. The Journal of Futures Markets, 13, 193-198. http://dx.doi.org/10.1002/fut.3990130206

Gonzalo, J., \& Granger, C. (1995). Estimation of common long-memory components in cointegrated systems. Journal of Business \& Economic Statistics, 13, 27-35.

Hasbrouck, J. (1995). One security, many markets: Determining the contributions to price discovery. Journal of Finance, 50, 1175-1199. http://dx.doi.org/10.1111/j.1540-6261.1995.tb04054.x

Jabbour, G. Y. (1994). Prediction of future currency exchange rates from current currency futures prices: The case of GM and JY. Journal of Futures Markets, 14, 25-36. http://dx.doi.org/10.1002/fut.3990140104

Jiang, L., Fung, J. K. W., \& Cheng, L. T. W. (2001). The lead-lag relation between spot and futures markets under different short-selling regimes. The Financial Review, 38, 63-88. http://dx.doi.org/10.1111/j.1540-6288.2001.tb00020.x

Jochum, C., \& Kodres, L. (1998). Does the introduction of futures on emerging market currencies destabilize the underlying currencies? IMF Staff Papers, 45(3).

Johansen, S. (1988). Statistical analysis of cointegration vectors. Journal of Economic Dynamics and Control, 12, 231-254. http://dx.doi.org/10.1016/0165-1889(88)90041-3

Kawaller, I. G., Koch, P. D., \& Koch, T. W. (1987). The temporal price relationship between S\&P 500 futures and the S\&P 500 index. Journal of Finance, 42, 1309-1329. 
Martens, M., \& Kofman, P. (1998). The inefficiency of Reuters foreign exchange quotes. Journal of Banking and Finance, 22, 347-366. http://dx.doi.org/10.1016/S0378-4266(98)00004-1

Parhizgari, A. M., Dandapani, K., \& Bhattachayra, A. (1994). Global market place and causality. Global Finance Journal, 5(1), 121-140. http://dx.doi.org/10.1016/1044-0283(94)90018-3

Phillips, P. C. B., \& Perron, P. (1988). Testing for a unit root in time series regression. Biometrika, 75, 335-346. http://dx.doi.org/10.1093/biomet/75.2.335

Poskitt, R. (2010). Price discovery in electronic foreign exchange markets: The Sterling/Dollar market. The Journal of Futures Markets, 30, 590-606.

Rosenberg, J. V., \& Traub, L. G. (2009). Price discovery in the foreign currency futures and spot market. The Journal of Derivatives, Winter, 7 -25. http://dx.doi.org/10.3905/JOD.2009.17.2.007

Schlusche, B. (2009). Price formation in spot and futures markets: Exchange traded funds vs. index futures. The Journal of Derivatives, Winter, 26-40. http://dx.doi.org/10.3905/JOD.2009.17.2.026

Stoll, H. R., \& Whaley, R. E. (1990). The dynamics of stock index and stock index futures returns. Journal of Financial and Quantitative Analysis, 25, 441-468. http://dx.doi.org/10.2307/2331010

Shyy, G., Vijayraghavan, V., \& Scott-Quinn, B. (1996). A further investigation of the lead-lag relationship between the cash market and stock index futures markets with the use of bid/ask quotes: The case of France. $\begin{array}{lllll}\text { The Journal } & \text { Futures }\end{array}$ http://dx.doi.org/10.1002/(SICI)1096-9934(199606)16:4<405::AID-FUT3>3.0.CO;2-M

Tang, Y. N., Mak, S. C., \& Choi, D. F. S. (1992). The causal relationship between stock index futures and cash index prices in Hong Kong. Applied Financial Economics, 2, 187-190. http://dx.doi.org/10.1080/758527099

Tornell, A., \& Yuan, C. (2012). Speculation and hedging in the currency futures markets: Are they informative to the spot exchange rates. The Journal of Futures Markets, 32, 122-151. http://dx.doi.org/10.1002/fut.20511

Tse, Y. K., Xiang, J., \& Fung, J. K. W. (2006). Price discovery in the foreign exchange futures market. The Journal of Futures Markets, 26, 1131-1143. http://dx.doi.org/10.1002/fut.20229

Tse, Y. K. (1995). Lead-lag relationship between spot index and futures price of the Nikkei stock average. Journal of Forecasting, 14, 553-563. http://dx.doi.org/10.1002/for.3980140702

\section{Notes}

Note1. In 2010 South Africa joined the group of leading emerging market economies known as BRIC (Brazil, Russia, India and China) and the group was subsequently renamed BRICS.

Note 2. Chinese renminbi futures data are not available for the duration of our study and Indian rupee futures are not traded on the Chicago Mercantile Exchange.

Note 3. The Brazilian real futures on CME have thirteen consecutive expiration months listed and two deferred March quarterly months. The Russian ruble futures have twelve consecutive months listed in addition to sixteen March quarterly months. Lastly, the South African rand has thirteen consecutive calendar months listed, as well as two deferred March quarterly cycle months. Trading in all these contracts are sparse on a daily basis, yielding high frequency analysis infeasible.

Note 4. Based on Bai and Perron (2003), computing the estimates $\left(\delta^{\wedge}(\{\mathrm{T} j\})\right.$, where $\delta_{=}=\left(\delta_{-}(1, \ldots,) \delta_{-}(\mathrm{m}+1)\right)^{\wedge \prime}$ on the $\mathrm{m}-$ partition $\left(\mathrm{T}_{-} \mathrm{j}\right)$ and substituting these in the objective function, the resulting sum of the squared residual $\left(\mathrm{S}_{-} \mathrm{T}\left(\mathrm{T}_{-} 1, \ldots, \mathrm{T}_{-} \mathrm{n}\right)\right)$ and the estimated breakpoints $\left(\left(\mathrm{T}_{-} 1\right)^{\wedge}, \ldots,\left(\mathrm{T} \_\mathrm{m}\right)^{\wedge}\right)$ are such that $\left(\left(\mathrm{T}_{-} 1\right)^{\wedge}, \ldots,\left(\mathrm{T} \_\mathrm{m}\right)^{\wedge}\right)=$ [ $\operatorname{argmin} \Omega_{-}\left(\mathrm{T}_{-} 1, \ldots, \mathrm{T}_{-} \mathrm{m}\right) \mathrm{S}_{-} \mathrm{T}\left(\mathrm{T}_{-} 1, \ldots, \mathrm{T}_{-} \mathrm{nm}\right)$, where the minimization is taken over all partitions $\left(\mathrm{T} \_1, \ldots, \mathrm{m}\right)$.

Note 5. For further details on how the SupF statistics and the "double maximum" statistics are estimated and the critical values estimated by the authors, please refer to Bai and Perron (1998 and 2003).

Note 6. SupF_T $(|-1+1-| 1)$ is equivalent to doing $(1+1)$ tests of the null of no structural changes versus the alternate of a single change.

Note 7. Even though Bai and Perron (2000) argue that a small trimming may create size distortions when allowing for serial correlation or for the different variances of the errors when working with small sample size 
(i.e., 100 or less), we believe that this will not be an issue in our study because our sample sizes are above 1,400 observations.

\section{Appendix}

Table A1.a. Descriptive Statistics

\begin{tabular}{|c|c|c|c|c|c|c|c|}
\hline Variable & Mean & Median & Std Dev & Skewness & Kurtosis & Minimum & Maximum \\
\hline \multicolumn{8}{|c|}{ Brazilian Real } \\
\hline Spot & 0.5088 & 0.5103 & 0.0688 & -0.0943 & -1.1909 & 0.3610 & 0.6419 \\
\hline Futures & 0.5033 & 0.5054 & 0.0692 & -0.1244 & -1.1815 & 0.3513 & 0.6370 \\
\hline Spot returns & 0.0329 & 0.0685 & 1.1388 & -0.4320 & 7.8770 & -6.6929 & 8.3400 \\
\hline Futures returns & 0.0329 & 0.0855 & 1.1756 & -0.5427 & 7.1727 & -7.3980 & 9.0416 \\
\hline Futures volume & 208.47 & 75.00 & 463.11 & 7.24 & 79.55 & 0.00 & 8003.00 \\
\hline Futures open interest & 3763.89 & 2765.00 & 2788.56 & 0.78 & -0.37 & 0.00 & 12367.00 \\
\hline \multicolumn{8}{|c|}{ South African Rand } \\
\hline Spot & 0.1402 & 0.1405 & 0.0160 & -0.6804 & 0.9674 & 0.0863 & 0.1773 \\
\hline Futures & 0.1388 & 0.1393 & 0.0161 & -0.6761 & 0.9299 & 0.0844 & 0.1754 \\
\hline Spot returns & -0.0001 & 0.0000 & 0.0130 & -0.7656 & 19.3430 & -0.1484 & 0.1031 \\
\hline Futures returns & -0.0001 & 0.0001 & 0.0125 & -0.0744 & 11.3643 & -0.1006 & 0.1033 \\
\hline Futures volume & 280.22 & 124.00 & 503.37 & 5.81 & 53.79 & 0.00 & 7814.00 \\
\hline Futures open interest & 4303.78 & 3689.00 & 2102.48 & 1.05 & 0.88 & 0.00 & 12847.00 \\
\hline \multicolumn{8}{|c|}{ Russian Ruble } \\
\hline Spot & 0.0361 & 0.0360 & 0.0034 & 0.0492 & -0.4986 & 0.0275 & 0.0432 \\
\hline Futures & 0.0353 & 0.0352 & 0.0039 & -0.3335 & -0.2292 & 0.0238 & 0.0427 \\
\hline Spot returns & 0.0000 & 0.0001 & 0.0126 & 0.1017 & 93.4850 & -0.1545 & 0.1593 \\
\hline Futures returns & -0.0001 & 0.0003 & 0.0084 & -0.4260 & 35.9545 & -0.0771 & 0.1105 \\
\hline Futures volume & 156.57 & 1.00 & 371.49 & 5.11 & 38.15 & 0.00 & 4812.00 \\
\hline Futures open interest & 3989.00 & 3584.00 & 2472.04 & 0.41 & -0.73 & 2.00 & 10801.00 \\
\hline
\end{tabular}

This table reports summary statistics for the futures and spot prices and returns from January 3, 2005 to March 30, 2011. Futures returns are calculated from daily log price changes and are reported in percentage. The final matched sample for each currency contains 1,558 observations of the Brazilian real, 1,414 observations for the South African rand, and 1,560 observations for the Russian ruble. The sources of the data are Datastream, CSI (Commodity Systems, Inc.), and Tradestation. 
Table A1.b. Unit Root Tests

\begin{tabular}{|c|c|c|c|c|c|c|}
\hline \multirow[t]{2}{*}{ Type } & \multicolumn{2}{|c|}{ Augmented Dickey-Fuller Test } & \multicolumn{2}{|c|}{ Phillips-Perron Unit Root Test } & \multirow[b]{2}{*}{ Tau } & \multirow[b]{2}{*}{$\operatorname{Pr}<\mathrm{Tau}$} \\
\hline & $\mathrm{F}$ & $\operatorname{Pr}>\mathrm{F}$ & Rho & $\operatorname{Pr}<$ Rho & & \\
\hline \multicolumn{7}{|l|}{ Real Spot } \\
\hline Single Mean & 2.85 & 0.3398 & -6.88 & 0.2836 & -2.11 & 0.2390 \\
\hline Trend & 3.22 & 0.5287 & -12.40 & 0.2941 & -2.61 & 0.2761 \\
\hline \multicolumn{7}{|l|}{ Real Futures } \\
\hline Single Mean & 2.80 & 0.3518 & -7.06 & 0.2716 & -2.14 & 0.2275 \\
\hline Trend & 3.08 & 0.5573 & -12.55 & 0.2868 & -2.62 & 0.2708 \\
\hline \multicolumn{7}{|c|}{ Real Spot Returns } \\
\hline Single Mean & 472.12 & 0.0010 & -1646.70 & 0.0001 & -41.79 & $<.0001$ \\
\hline Trend & 472.03 & 0.0010 & -1646.93 & 0.0001 & -41.78 & $<.0001$ \\
\hline \multicolumn{7}{|c|}{ Real Futures Returns } \\
\hline Single Mean & 458.34 & 0.0010 & -1696.02 & 0.0001 & -43.14 & $<.0001$ \\
\hline Trend & 458.28 & 0.0010 & -1696.28 & 0.0001 & -43.14 & $<.0001$ \\
\hline \multicolumn{7}{|l|}{ Ruble Spot } \\
\hline Single Mean & 1.53 & 0.6799 & -8.63 & 0.1873 & -2.08 & 0.2532 \\
\hline Trend & 1.95 & 0.7861 & -10.60 & 0.3970 & -2.33 & 0.4191 \\
\hline \multicolumn{7}{|l|}{ Ruble Futures } \\
\hline Single Mean & 1.15 & 0.7770 & -4.33 & 0.5034 & -1.41 & 0.5770 \\
\hline Trend & 1.96 & 0.7844 & -6.03 & 0.7424 & -1.78 & 0.7153 \\
\hline \multicolumn{7}{|c|}{ Ruble Spot Returns } \\
\hline Single Mean & 760.20 & 0.0010 & -2127.31 & 0.0001 & -60.68 & $<.0001$ \\
\hline Trend & 759.74 & 0.0010 & -2127.31 & 0.0001 & -60.66 & $<.0001$ \\
\hline \multicolumn{7}{|c|}{ Ruble Futures Returns } \\
\hline Single Mean & 394.14 & 0.0010 & -1410.90 & 0.0001 & -35.85 & $<.0001$ \\
\hline Trend & 394.10 & 0.001 & -1411.12 & 0.0001 & -35.84 & $<.0001$ \\
\hline \multicolumn{7}{|l|}{ Rand Spot } \\
\hline Single Mean & 2.50 & 0.4298 & -10.09 & 0.132 & -2.49 & 0.1175 \\
\hline Trend & 2.61 & 0.6525 & -11.14 & 0.3634 & -2.3 & 0.4319 \\
\hline \multicolumn{7}{|l|}{ Rand Futures } \\
\hline Single Mean & 2.39 & 0.4581 & -9.44 & 0.1544 & -2.42 & 0.1366 \\
\hline Trend & 2.50 & 0.6753 & -10.29 & 0.4166 & -2.21 & 0.4859 \\
\hline \multicolumn{7}{|c|}{ Rand Spot Returns } \\
\hline Single Mean & 363.17 & 0.0010 & -1399.76 & 0.0001 & -37.54 & $<.0001$ \\
\hline Trend & 363.50 & 0.0010 & -1400.61 & 0.0001 & -37.54 & $<.0001$ \\
\hline \multicolumn{7}{|c|}{ Rand Futures Returns } \\
\hline Single Mean & 325.92 & 0.0010 & -1343.31 & 0.0001 & -36.13 & $<.0001$ \\
\hline Trend & 326.18 & 0.0010 & -1344.19 & 0.0001 & -36.13 & $<.0001$ \\
\hline
\end{tabular}

Table A1.c. Johansen Cointegration Rank Test

\begin{tabular}{|c|c|c|c|c|c|}
\hline & H0: & $\mathrm{H} 1:$ & & & Critical \\
\hline & Rank $=r$ & Rank $>r$ & Eigenvalue & Trace & Value \\
\hline \multirow[t]{2}{*}{ Real } & 0 & 0 & 0.108 & 180.284 & 12.21 \\
\hline & 1 & 1 & 0.0017 & 2.5969 & 4.14 \\
\hline \multirow[t]{2}{*}{ Ruble } & 0 & 0 & 0.017 & 26.7486 & 12.21 \\
\hline & 1 & 1 & 0 & 0.0304 & 4.14 \\
\hline \multirow[t]{2}{*}{ Rand } & 0 & 0 & 0.1542 & 236.3 & 12.21 \\
\hline & 1 & 1 & 0 & 0.009 & 4.14 \\
\hline
\end{tabular}

